\title{
The Postoperative Analgesic Effect of
} Ultrasound-Guided Bilateral Transversus Abdominis Plane Combined with Rectus Sheath
Blocks in Laparoscopic Hepatectomy:
A Randomized Controlled Study

This article was published in the following Dove Press journal: Therapeutics and Clinical Risk Management

\author{
Xiaoyun Lu ${ }^{1,2, *^{*}}$ \\ Ping Yu (1D) ${ }^{1,2, *^{*}}$ \\ Chaopeng Ou (iD) ${ }^{1,2, * *}$ \\ Junchao Wang ${ }^{1,2}$ \\ Zhongguo Zhou ${ }^{1,3}$ \\ Renchun Lai (iD) ${ }^{1,2}$ \\ 'Collaborative Innovation Center for \\ Cancer Medicine, State Key Laboratory \\ of Oncology in South China, Sun Yat-Sen \\ University Cancer Center, Guangzhou, \\ Guangdong, People's Republic of China; \\ ${ }^{2}$ Department of Anesthesiology, Sun Yat- \\ Sen University Cancer Center, \\ Guangzhou, Guangdong, People's \\ Republic of China; ${ }^{3}$ Department of Liver \\ Surgery, Sun Yat-Sen University Cancer \\ Center, Guangzhou, Guangdong, People's \\ Republic of China
}

*These authors contributed equally to this work.
Correspondence: Zhongguo Zhou;

Renchun Lai

Email zhouzhg@sysucc.org.cn;

lairench@sysucc.org.cn
Background: Our aim was to investigate the postoperative analgesic effect of ultrasound (US)-guided bilateral transversus abdominis plane (TAP) blocks combined with rectus sheath blocks (RSBs) in laparoscopic hepatectomy.

Patients and Methods: A total of 126 patients were allocated into two groups for analysis. Group $1(n=63)$ did not receive any local anesthetics. Group $2(n=63)$ received US-guided bilateral TAP blocks and RSBs using $20 \mathrm{~mL} 0.25 \%$ ropivacaine in each block. Postoperative pain scores, the dose of intraoperative remifentanil, $24 \mathrm{~h}$ consumption of oxycodone, adverse events such as postoperative dizziness, nausea and vomiting, and the length of postoperative hospital stay were recorded.

Results: In the postanesthesia care unit, patients in group 2 had significantly lower pain visual analog scale (VAS) scores at rest than those in group $1(P<0.001)$. The VAS scores both at rest and during movement were significantly lower in group 2 than in group 1 at 2, 4 and 6 h postoperatively (all $P<0.001$ ). There was no difference in VAS scores between the two groups at rest $24 \mathrm{~h}$ postoperatively $(P=0.477)$. However, the VAS score during movement at $24 \mathrm{~h}$ in group 2 was significantly lower than that in group $1(P<0.001)$. No significant differences in the incidence of adverse events or the dose of intraoperative remifentanil were observed between the two groups (all $P>0.05$ ). Patients in group 2 had a significantly lower $24 \mathrm{~h}$ consumption of oxycodone than patients in group $1(P<0.001)$. The mean length of postoperative hospital stay of group 2 was shorter than that of group 1 $(P=0.032)$.

Conclusion: US-guided bilateral TAP blocks combined with RSBs provide effective postoperative analgesia for laparoscopic hepatectomy, and they could shorten the postoperative hospital stay without increasing the incidence of adverse events from opioids.

Keywords: laparoscopic hepatectomy, analgesia, transversus abdominis plane block, rectus sheath block, ultrasound

\section{Introduction}

Laparoscopic hepatectomy offers a safe and feasible option primarily for the excision of hepatic neoplasms. Patients can quickly recover to normal function with minimal abdominal wall injury. ${ }^{1}$ Nevertheless, persistent pain due to laparoscopy itself and 
postoperative trauma affect the recovery of patients, prolong the hospital stay, and cause stress reactions and related complications, including cardiovascular and cerebrovascular accidents as well as gastrointestinal and neuroendocrine dysfunction. ${ }^{2-4}$ Currently, there is no uniform standard for analgesia during laparoscopic hepatectomy.

Transversus abdominis plane (TAP) blocks and rectus sheath blocks (RSBs) have been widely studied and used in abdominal surgery to provide somatic anesthesia of the anterolateral and middle abdominal wall. ${ }^{5-9}$ In the past 10 years, many studies have shown the effectiveness of TAP blocks and RSBs in laparoscopic surgeries, such as hysterectomy, cholecystectomy and herniorrhaphy., ${ }^{8,10-12}$ Although multimodal perioperative analgesia can significantly relieve postoperative pain, there are few relevant studies on ultrasound (US)-guided bilateral TAP blocks combined with RSBs for postoperative analgesia in laparoscopic hepatectomy.

Therefore, the aim of this prospective, randomized clinical study was to investigate the postoperative analgesic effect of US-guided bilateral TAP blocks combined with RSBs in laparoscopic hepatectomy.

\section{Patients and Methods}

\section{Patient Selection}

This was a prospective randomized study performed between Jan. 2019 and Dec. 2019 at Sun Yat-sen University Cancer Center. This study was approved by the Research Ethics Committee in Sun Yat-sen University Cancer Center, and written informed consent was obtained from all patients participating in the trial. The trial was registered prior to patient enrollment at www.chictr.org.cn (ChiCTR1900020877, Principal investigator: Renchun Lai, Date of registration: 2019-01-21). Other inclusion criteria were as follows: (1) grades I-III according to the American Society of Anesthesiologists Physical Status Classification System (ASA), (2) older than 18 years, (3) no history of motion sickness, nausea or vomiting, or chronic pain, and (4) with resectable, left or right liver lesions and the resection range expected to be greater than or equal to 1 liver segment. The exclusion criteria were as follows: (1) unwillingness to participate, (2) allergy for local anesthetics including ropivacaine, (3) ASA class IV-VI, (4) conversion to open hepatectomy, (5) history of myocardial infarction, stroke and heart failure in the past 12 months, and (6) morbid obesity (body mass index $\geq 35$ ).

\section{Randomization and Grouping}

Randomization was performed according to a random number table, and then the allocation was sealed into an opaque envelope. Patients were randomized into two groups: Group 1 received no local anesthetics; Group 2 received US-guided bilateral TAP blocks combined with RSBs using $20 \mathrm{~mL} 0.25 \%$ ropivacaine in each block ( $80 \mathrm{~mL}$ in total).

\section{Surgical Procedure and Analgesic Methods}

Laparoscopic hepatectomy (Including major hepatectomy and hemi-hepatectomy) was performed by the same surgical team. Four to five puncture holes were made in the abdomen wall according to the location of the resected liver, and a Joel-Cohen incision was used to take the specimen in which the length depended on the size of the specimen. One or two abdominal drainage tubes were routinely placed near the hepatic section surface and fixed on the abdominal skin.

All patients received the same standardized anesthesia scheme. For induction, dexmedetomidine $(0.5 \mu \mathrm{g} / \mathrm{kg})$, propofol $(1.5-2 \mathrm{mg} / \mathrm{kg})$, sufentanil $(0.5 \mu \mathrm{g} / \mathrm{kg})$ and cisatracurium $(0.15-0.2 \mathrm{mg} / \mathrm{kg})$ were used. For maintenance, oxygen/air sevoflurane (2-3\%), remifentanil (0.05-0.2 $\left.\mu \mathrm{g} \cdot \mathrm{kg}^{-1} \cdot \mathrm{min}^{-1}\right) \quad$ and cisatracurium $\quad(0.15-0.2$ $\mu \mathrm{g} \cdot \mathrm{kg}^{-1} \cdot \mathrm{min}^{-1}$ ) were used. Palonosetron was administered during surgery.

The blocks were performed by one of the authors who was experienced in the US-guided nerve block technique, did not know the grouping and was not involved in the data collection.

The block was performed utilizing a US transducer (linear 6-13 MHz, SonoSite M-Turbo ${ }^{\circledR}$, Brothell, USA) (covered with a sterile sheath) and a 22-gauge $12-\mathrm{cm}$ insulated needle (Stimuplex ${ }^{\circledR}$ A, B-Braun Medical, Melsungen, Germany). All the procedures followed the strict aseptic principle. First, at the horizontal level of the umbilicus, the linea alba was visualized using an ultrasonic probe. Then, the probe was moved laterally to identify the rectus abdominis muscle. An RSB was performed using an insulated needle and the in-plane technique to insert the endpoint in the plane between the rectus muscle and the posterior rectus sheath. Twenty milliliters of $0.25 \%$ ropivacaine was injected. The probe was then moved further laterally, below the costal margin at the midaxillary line, to visualize the three muscle layers of 
the external oblique, internal oblique and transversus abdominis muscles. A TAP block was performed with ropivacaine injected in the plane between the internal oblique and transversus abdominis muscles. The spread of solutions was visualized under ultrasound guidance so that the solutions could be distributed evenly within these planes.

All patients received patient-controlled intravenous analgesia (PCIA) to relieve pain after the operation. One hundred milliliters of $1 \mathrm{mg} / \mathrm{mL}$ oxycodone was used in the analgesic pump. The flow rate of the pump was $1 \mathrm{~mL} / \mathrm{h}$ with a bolus of $2 \mathrm{~mL}$ and $5 \mathrm{~min}$ of lockout time. At the end of the operation, a PCIA pump was inserted into the intravenous infusion tube. The pump was routinely removed $48 \mathrm{~h}$ after the operation.

\section{Outcome Measurements}

The primary endpoint was postoperative pain scores measured using a visual analog scale (VAS) ranging from $0-10$, with 0 denoting no pain and 10 denoting the worst imaginable pain, in the postanesthesia care unit (PACU) and at 2, 6, 12, and $24 \mathrm{~h}$ after the operation both at rest (VAS R) and during movement (VAS M).

The secondary endpoint was the dose of intraoperative remifentanil, $24 \mathrm{~h}$ consumption of oxycodone, adverse events such as postoperative dizziness, nausea and vomiting, and the length of postoperative hospital stay.

\section{Statistical Analysis}

Based on previously published data, ${ }^{13,14}$ the mean difference (standard deviation, SD) in the VAS pain score during movement $24 \mathrm{~h}$ after the operation in the control group was $5.4(\mathrm{SD}=2.5)$, and a $30 \%$ reduction in the VAS pain score was hypothesized to be effective in the bilateral TAP blocks and RSBs group. Sixty-five patients in each group were required for $90 \%$ power and a two-sided $\alpha$ of $5 \%$, allowing for a $15 \%$ dropout rate.

The continuous variables normally distributed were described as the means \pm standard deviation (SD). Mean differences between the groups were compared using an independent $t$-test. Continuous data that were not normally distributed were presented with median and interquartile ranges and compared using the Mann-Whitney $U$-test. The categorical variables were described as frequencies and percentages and compared using a chi-square test or Fisher's exact test. The statistical analyses were performed using SPSS, version 22.0 (SPSS Inc., Chicago, IL, USA) and Microsoft Excel 2013 (Microsoft Corporation,
Redmond, Washington, USA). A two-sided $P<0.05$ was thought to be statistically significant.

\section{Results \\ Baseline Characteristics}

Patient selection is shown in Figure 1. In total, 130 patients undergoing laparoscopic hepatectomy enrolled were randomized into two groups in the study. Finally, 126 patients included were analyzed. Table 1 summarizes the demographic and operative characteristics according to the block. Among 126 patients, 63 patients were in group 1 , and 63 patients were in group 2. Compared with patients in group 1, there were more male patients and taller patients in group $2(P<0.05)$. There were no differences in age, weight, BMI, ASA class, duration of surgery or duration of anesthesia between the groups.

There were no complications related to the block performance. No symptoms of local anesthesia systemic toxicity appeared.

\section{Comparison of Postoperative VAS Scores} Pain scores were measured using the VAS at rest and during movement at different times after the operation (shown in Table 2, Figures 2 and 3).

In the PACU, patients in group 2 had significantly lower VAS scores at rest than those in group $1(1[0,1]$ vs $2[1,2], P<0.001)$.

At 2, 4, and $6 \mathrm{~h}$ postoperatively, the VAS scores both at rest and during movement were significantly lower in group 2 than in group 1 (all $P<0.001$ ).

At $24 \mathrm{~h}$ postoperatively, there was no difference in VAS scores between the two groups at rest $(0[0,1]$ vs 0 $[0,1], P=0.477)$. However, the VAS score during movement in group 2 was significantly lower than that in group $1(3[3,4]$ vs $4[3,5], P<0.001)$.

\section{Incidence of Adverse Events, Opioid Usage, Length of Postoperative Hospital Stay and Surgery Complications}

As shown in Table 3, no significant differences in the incidence of adverse events (dizziness, nausea, vomiting) were observed between the two groups (all $P>0.05$ ); in other words, the performance of the block did not increase the incidence of adverse events.

The patients in group 2 received a lower mean cumulative intraoperative remifentanil dose than those in group 1 , but there was no statistically significant difference 


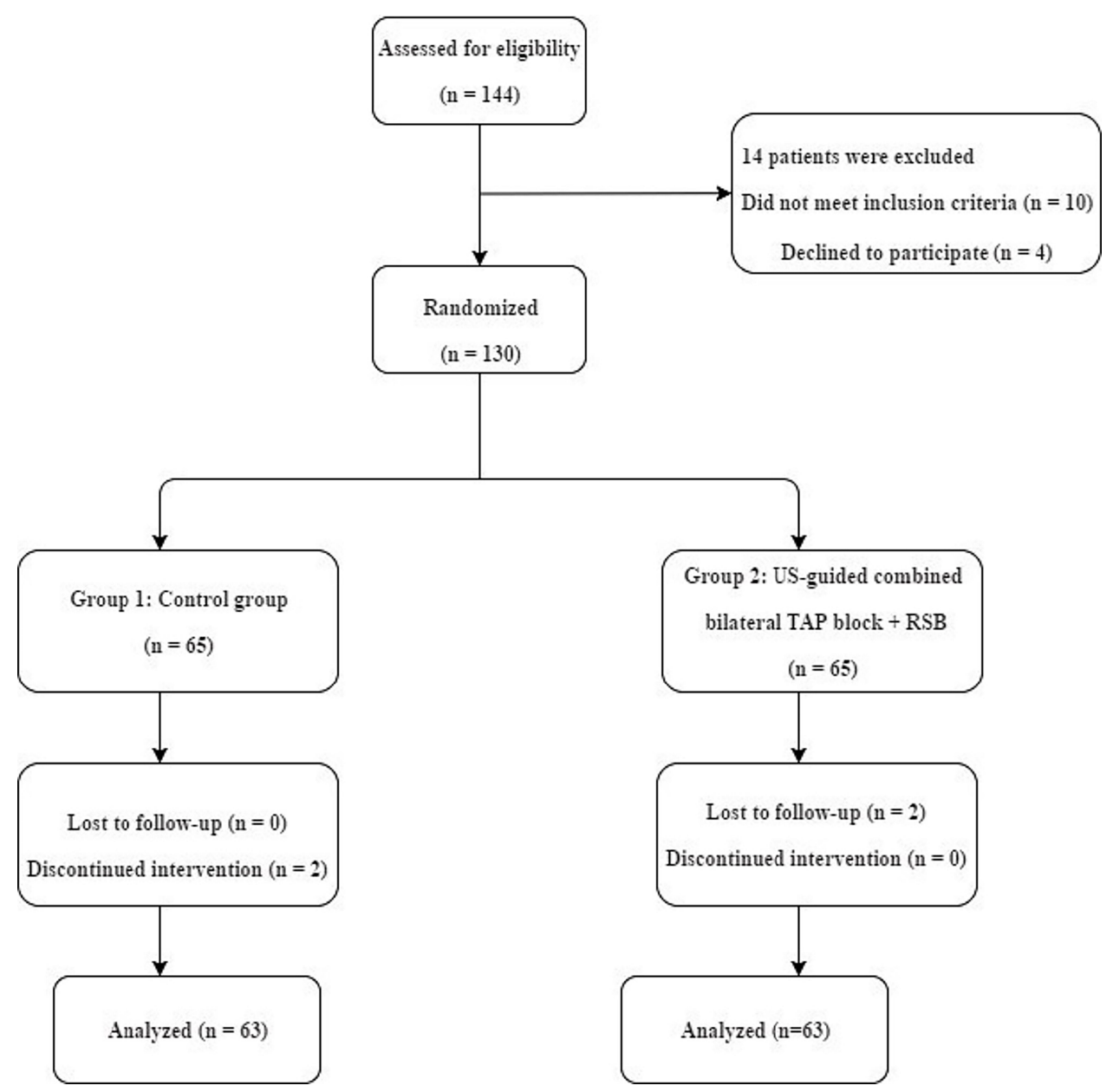

Figure I Flow diagram of patient selection.

$(736.5 \pm 417.8 \mu \mathrm{g}$ vs $738.2 \pm 347.6 \mu \mathrm{g}, P=0.982)$. The patients in group 2 had a significantly lower 24 $\mathrm{h}$ consumption of oxycodone than those in group 1 (26 $[24,28] \mathrm{mg}$ vs $28[26,32] \mathrm{mg}, P<0.001)$. The mean length of postoperative hospital stay in group 2 was significantly shorter than that in group $1(5.3 \pm 1.4$ days vs $5.8 \pm 1.6$ days, $P=0.032$ ), which meant that the performance of the block could shorten the postoperative hospital stay.

No patient died in either group. There was no significant difference in surgery complications between the two groups ( $P=0.548$; Table 3 ). None had pulmonary complications or intestinal fistula. Nine patients with venous gas embolism remained in the study although receiving active treatment. One patient with intestinal obstruction in group 1 and one patient with bile leakage in group 2 underwent conservative treatment and were discharged from hospital after confirmed recovery.

\section{Discussion}

The advantages of laparoscopic hepatectomy are that it is minimally invasive and has faster recovery of gastrointestinal function and a shorter hospital stay than traditional open hepatectomy. ${ }^{1}$ However, some patients undergoing laparoscopic hepatectomy still suffer from incisional pain, visceral pain, shoulder pain and other discomforts because of incisional and visceral trauma, carbon dioxide stimulation of the abdominal visceral nerve and somatic nerve and other factors. ${ }^{15,16}$ One study even showed that incisional pain contributed more than visceral pain in laparoscopic pain. ${ }^{17}$ Therefore, effective perioperative analgesia is essential for patients to accelerate postoperative rehabilitation. A regional block of the abdominal wall, when used as a part of multimodal analgesia, can make the analgesic effect more obvious and reduce the dosage of analgesics. 
Table I Baseline Characteristics of Patients

\begin{tabular}{|c|c|c|c|}
\hline Characteristic & $\begin{array}{l}\text { Group I } \\
(n=63)\end{array}$ & $\begin{array}{l}\text { Group } 2 \\
(n=63)\end{array}$ & $P$ \\
\hline Sex, n (\%) & & & $0.001^{\mathrm{a}}$ \\
\hline Male & 45 (7I.4) & $59(93.7)$ & \\
\hline Female & $18(28.6)$ & $4(6.3)$ & \\
\hline Age (years) & $51.4 \pm 12.5$ & $52.9 \pm 11.5$ & $0.450^{\mathrm{b}}$ \\
\hline Weight (kg) & $60.9 \pm 11.3$ & $64.8 \pm 9.9$ & $0.054^{\mathrm{b}}$ \\
\hline Height $(\mathrm{cm})$ & $164.8 \pm 6.8$ & $168.1 \pm 5.9$ & $0.003^{b}$ \\
\hline BMI $\left(\mathrm{kg} / \mathrm{m}^{2}\right)$ & $22.3 \pm 3.4$ & $22.8 \pm 2.8$ & $0.358^{\mathrm{b}}$ \\
\hline ASA class, n (\%) & & & $0.280^{\mathrm{a}}$ \\
\hline 1 & $32(50.8)$ & $29(46.0)$ & \\
\hline II & $27(42.9)$ & $33(52.4)$ & \\
\hline III & $4(6.3)$ & I (I.6) & \\
\hline $\begin{array}{l}\text { Duration of surgery } \\
\text { (min) }\end{array}$ & $140.5 \pm 38.9$ & $136.4 \pm 59.1$ & $0.638^{\mathrm{b}}$ \\
\hline $\begin{array}{l}\text { Duration of anesthesia } \\
(\mathrm{min})\end{array}$ & $|7| . \mid \pm 38.6$ & $174.7 \pm 59.1$ & $0.689^{\mathrm{b}}$ \\
\hline
\end{tabular}

Notes: Results are presented as means \pm SD for age, weight, height, BMI, duration of surgery and duration of anesthesia or $\mathrm{n}(\%)$ for sex and ASA class. ${ }^{\mathrm{a}}$ Using Chisquared test or Fisher's exact test; ${ }^{b}$ using independent $t$-test. $P<0.05$ was considered statistically significant.

Abbreviations: BMI, body mass index; ASA, American Society of Anesthesiologist; SD, standard deviation.

The classic lateral TAP block involves the sensory area of the anterolateral abdominal wall where the T10-L1 nerves innervate, while the RSB involves the sensory area of the abdominal wall where the T6-9 nerves innervate. The combination of a classic lateral TAP block and an RSB may be effective in relieving postoperative pain. Therefore, we focused on the postoperative analgesic effect of US-guided bilateral TAP blocks combined with RSBs in laparoscopic hepatectomy.

There is a lack of data concerning this combination in laparoscopic hepatectomy. A randomized controlled study on patients undergoing major upper abdominal surgery showed that the combination of the classic TAP block with an RSB resulted in significant opioid-sparing effects both in the intraoperative and postoperative periods and lower VAS scores at $6 \mathrm{~h}(2.19$ [1-4] vs 4.8 [3-7]) and 24 h $\left(2.5\right.$ [2-6] vs 4 [3-7]) postoperatively at rest. ${ }^{18}$ In the current study, the patients in the bilateral TAP blocks and RSBs group had lower $24 \mathrm{~h}$ consumption of oxycodone in the postoperative period than the control group $(26[24,28]$ vs $28[26,32], P<0.001)$. However, there was no statistically significant difference in the cumulative intraoperative remifentanil dose $(736.5 \pm 417.8 \mu \mathrm{g}$ vs $738.2 \pm 347.6 \mu \mathrm{g}$, $P=0.982$ ) between the two groups, which was inconsistent with the results of the above study. The patients in the block group had lower VAS scores both at rest and during movement at 2, 4, and $6 \mathrm{~h}$ postoperatively than those in the control group. There was no difference in VAS scores between the two groups at rest $(0[0,1]$ vs $0[0,1]$, $P=0.477)$ at $24 \mathrm{~h}$ postoperatively, which was different from the results of the above study. This difference might be due to gradual metabolism of the local anesthetic on the fascial planes of the abdominal wall. The effect of analgesia was reduced. Generally, patients increased their movement, such as moving in bed and ambulating at 24 $\mathrm{h}$ postoperatively, so the VAS scores were relatively higher than those at 2, 4, and $6 \mathrm{~h}$ postoperatively in our study. The pain score during movement was significantly lower in the block group than in the control group, even at $24 \mathrm{~h}$.

Opioids may be associated with some side effects, such as dizziness, nausea, vomiting, pruritus, and respiratory depression. In our study, there were no patients with pruritus or respiration depression. No significant differences in the incidences of dizziness, nausea, or vomiting were observed between the two groups, although the 24 $\mathrm{h}$ consumption of oxycodone in group 2 was lower than

Table 2 Comparison of Postoperative VAS Scores at Rest and During Movement at Different Time Points

\begin{tabular}{|c|c|c|c|c|c|c|}
\hline \multirow{2}{*}{$\begin{array}{l}\text { Time } \\
\text { (h) }\end{array}$} & \multicolumn{2}{|l|}{ Group I } & \multicolumn{2}{|l|}{ Group 2} & \multirow[t]{2}{*}{$P$ (Rest) } & \multirow[t]{2}{*}{ P (Movement) } \\
\hline & $\begin{array}{l}\text { Rest Median } \\
\text { (IQR) }\end{array}$ & $\begin{array}{l}\text { Movement Median } \\
\text { (IQR) }\end{array}$ & $\begin{array}{l}\text { Rest Median } \\
\text { (IQR) }\end{array}$ & $\begin{array}{l}\text { Movement Median } \\
\text { (IQR) }\end{array}$ & & \\
\hline PACU & $2(I, 2)$ & - & I $(0,1)$ & - & $<0.001$ & - \\
\hline 2 & $I(I, 2)$ & $4(3,5)$ & $0(0,1)$ & $3(2,3)$ & $<0.001$ & $<0.001$ \\
\hline 4 & $I(I, 2)$ & $4(3,5)$ & $0(0,0)$ & $3(2,3)$ & $<0.001$ & $<0.001$ \\
\hline 6 & $I(I, I)$ & $4(3,4)$ & $0(0,1)$ & $3(2,3)$ & $<0.001$ & $<0.001$ \\
\hline 24 & $0(0,1)$ & $4(3,5)$ & $0(0,1)$ & $3(3,4)$ & 0.477 & $<0.001$ \\
\hline
\end{tabular}

Notes: Results are presented as median (IQR) and compared using Mann-Whitney $U$-test. $P<0.05$ was considered statistically significant.

Abbreviations: PACU, postanesthesia care unit; IQR, interquartile range; VAS, visual analog scale. 


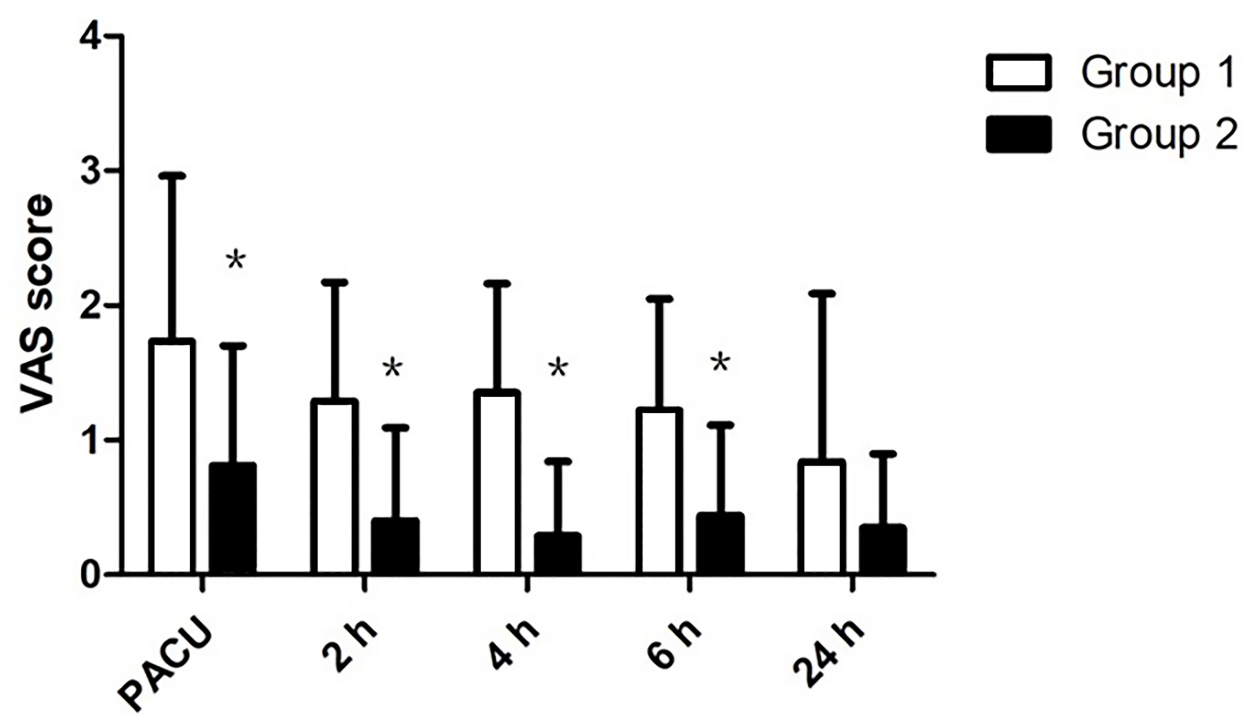

Figure 2 Comparison of postoperative pain scores at rest. Group I: Control group; Group 2: US-guided bilateral TAP blocks combined with RSBs (bilateral TAP blocks + RSBs). *There was a significant difference between the two groups $(P<0.05)$. In PACU, at 2, 4, 6 h postoperatively, patients in group 2 had statistically significant lower VAS score at rest compared with those in group I (all $\mathrm{P}<0.00 \mathrm{I}$ ). At $24 \mathrm{~h}$ postoperatively, there was no difference in VAS scores between two groups at rest $(\mathrm{P}=0.477)$.

Abbreviations: VAS, visual analog scale; PACU, postanesthesia care unit.

that in group 1. Unfortunately, the performance of the block did not decrease the incidence of adverse events. This might be attributed to the small sample size.

Additionally, as for surgery complications, there was no significant difference between the two groups, which indicated that the deviation caused by different surgical trauma was eliminated.

In recent years, US-guided regional blocks have gained popularity. Direct ultrasonographic visualization of all anatomical structures involved, the needle, and the spread of local anaesthetic increases both the safety and quality of regional blocks through optimal needle placement, avoiding inappropriate block and even injury to the abdominal viscera such as liver injury and intestinal puncture caused by the blind technique based on an anatomical landmarks. ${ }^{6}$ In our study, all the regional blocks were performed with the guidance of ultrasound which could help to reduce the bias caused by the differences between ultrasound and landmark approaches.

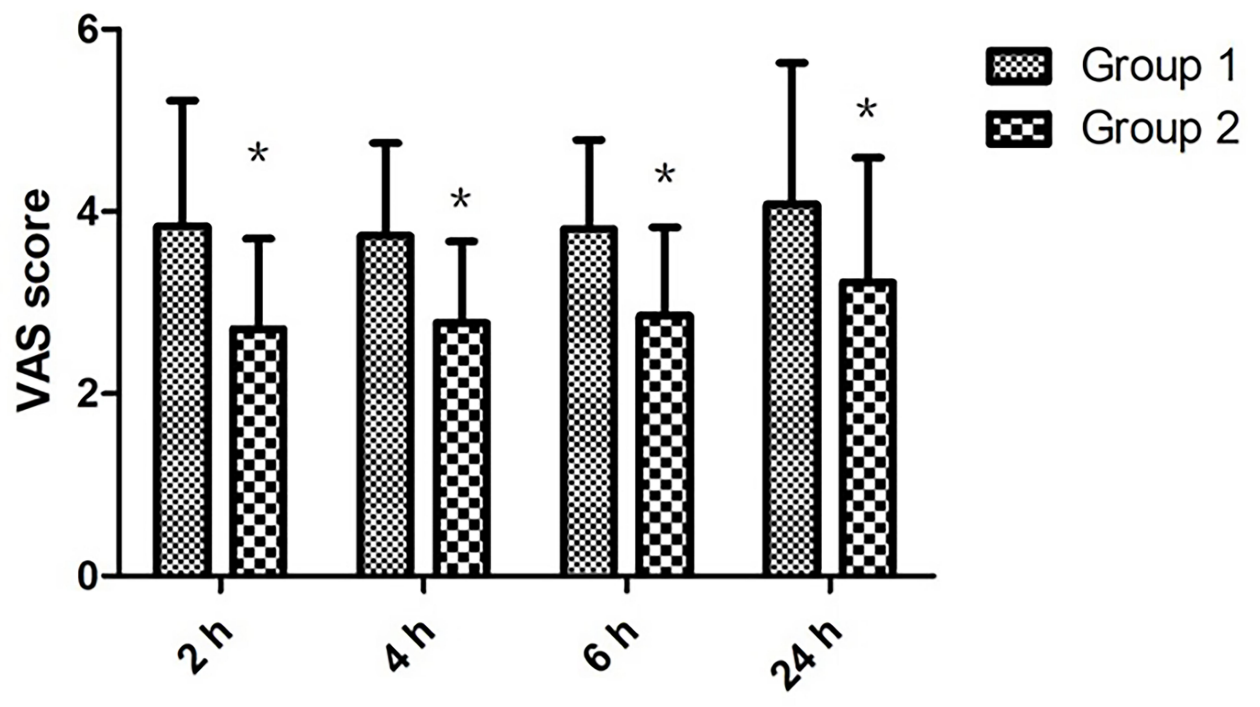

Figure 3 Comparison of postoperative pain scores during movement. Group I: Control group; Group 2: US-guided bilateral TAP blocks combined with RSBs (bilateral TAP blocks + RSBs). *There was a significant difference between the two groups $(P<0.05)$. At 2, 4, $6 \mathrm{~h}, 24 \mathrm{~h}$ postoperatively, VAS scores during movement were significantly lower in group 2 than group I (all $\mathrm{P}<0.00 \mathrm{I}$ ).

Abbreviation: VAS, visual analog scale. 
Table 3 Incidence of Adverse Events, Opioid Usage, The Length of Postoperative Hospital Stay and Surgery Complications

\begin{tabular}{|c|c|c|c|}
\hline Variable & $\begin{array}{l}\text { Group I } \\
(n=63)\end{array}$ & $\begin{array}{l}\text { Group } 2 \\
(n=63)\end{array}$ & $P$ \\
\hline $\begin{array}{l}\text { Dizzyness, n (\%) } \\
\text { No } \\
\text { Mild } \\
\text { Moderate } \\
\text { Severe }\end{array}$ & $\begin{array}{l}33(52.4) \\
19(30.2) \\
7(11.1) \\
4(6.3)\end{array}$ & $\begin{array}{l}27(42.9) \\
27(42.9) \\
7(11.1) \\
2(3.2)\end{array}$ & $0.444^{\mathrm{a}}$ \\
\hline $\begin{array}{l}\text { Nausea, n (\%) } \\
\text { No } \\
\text { Mild } \\
\text { Moderate } \\
\text { Severe }\end{array}$ & $\begin{array}{l}4 I(65 . I) \\
\text { I5 (23.8) } \\
5(7.9) \\
2(3.2)\end{array}$ & $\begin{array}{l}42(66.7) \\
17(27.0) \\
2(3.2) \\
2(3.2)\end{array}$ & $0.690^{\mathrm{a}}$ \\
\hline $\begin{array}{l}\text { Vomiting, } \mathrm{n}(\%) \\
\text { No } \\
\text { Mild } \\
\text { Moderate } \\
\text { Severe } \\
24 \mathrm{~h} \text { consumption of } \\
\text { oxycodone (mg) } \\
\text { IO remifentanil dose ( } \mu \mathrm{g}) \\
\text { Postoperative hospital stay } \\
\text { (days) }\end{array}$ & $\begin{array}{l}47(74.6) \\
11(17.5) \\
4(6.3) \\
1(1.6) \\
28(26,32) \\
738.2 \pm 347.6 \\
5.8 \pm 1.6\end{array}$ & $\begin{array}{l}48(76.2) \\
11(17.5) \\
4(6.3) \\
0 \\
26(24,28) \\
736.5 \pm 417.8 \\
5.3 \pm 1.4\end{array}$ & $\begin{array}{l}<0.001^{b} \\
0.982^{\mathrm{b}} \\
0.032^{\mathrm{c}}\end{array}$ \\
\hline $\begin{array}{l}\text { Surgery complications, } \\
\text { n (\%) } \\
\text { None } \\
\text { Pulmonary } \\
\text { complications } \\
\text { Venous gas embolism } \\
\text { Intestinal obstruction } \\
\text { Intestinal fistula } \\
\text { Bile leak }\end{array}$ & $\begin{array}{l}57(90.4) \\
0(0) \\
5(7.9) \\
1(1.6) \\
0(0) \\
0(0)\end{array}$ & $\begin{array}{l}58(92.1) \\
0(0) \\
4(6.4) \\
0(0) \\
0(0) \\
I(1.6)\end{array}$ & $0.548^{\mathrm{a}}$ \\
\hline
\end{tabular}

Notes: Results are presented as $\mathrm{n}(\%)$ for dizzy, nausea and vomiting or median (IQR) for 24h consumption of oxycodone or means \pm SD for 10 remifentanil dose and the length of postoperative hospital stay. 'Using Chi-squared test or Fisher's exact test; ' using Mann-Whitney $U$-test; ' using independent $t$-test. $P<0.05$ was considered statistically significant.

Abbreviations: IO, intraoperative; mg, milligram; $\mu \mathrm{g}$, microgram.

Our study had several limitations. First, this study was conducted at a single institution, and the sample size was small. Second, insufficient intraoperative analgesia was difficult to determine, although we could ensure hemodynamic stability and adequate muscle relaxation. Third, postoperative follow-up was not performed by a single observer, which could lead to interobserver bias in assessing the scores.

Therefore, further prospective clinical trials involving more institutions and a larger population are warranted to determine the exact postoperative analgesic effect of USguided bilateral TAP blocks combined with RSBs in laparoscopic hepatectomy.
In conclusion, US-guided bilateral TAP blocks combined with RSBs provide effective postoperative analgesia for laparoscopic hepatectomy, and they could shorten the postoperative hospital stay without increasing the incidence of adverse events from opioids. Ultrasound-guided transversus abdominis plane and rectus sheath blocks should be recommended in laparoscopic hepatectomy in the future.

\section{Abbreviations}

US, ultrasound; TAP, transversus abdominis plane; RSB, rectus sheath block; RSBs, rectus sheath blocks; PCIA, patient-controlled intravenous analgesia; PACU, postanesthesia care unit; VAS, visual analog scale; ASA, Anesthesiologists Physical Status Classification System; $\mathrm{SD}$, standard deviation; BMI, body mass index; IQR, interquartile range; IO, intraoperative.

\section{Data Sharing Statement}

We intend to share individual deidentified participant data which is included in the manuscript. No further specific data or study documents will be shared. The data shared will be accessible on the website (http://www.chictr.org.cn/addpro ject2.aspx) within six months after the trial received.

\section{Ethical Approval}

All procedures performed in studies involving human participants were in accordance with the ethical standards of the institutional and/or national research committee and with the 1964 Helsinki declaration and its later amendments or comparable ethical standards.

\section{Informed Consent}

Informed consent was obtained from every patient included in the study.

\section{Acknowledgments}

We would like to acknowledge and express our deepest gratitude to the participants of this study.

\section{Author contributions}

All authors made a significant contribution to the work reported, whether that is in the conception, study design, execution, acquisition of data, analysis and interpretation, or in all these areas; took part in drafting, revising or critically reviewing the article; gave final approval of the version to be published; have agreed on the journal to which the article has been submitted; and agree to be accountable for all aspects of the work. 


\section{Funding}

There is no funding to report.

\section{Disclosure}

The authors report no conflicts of interest for this work.

\section{References}

1. Tsai KY, Chen HA, Wang WY, Huang MT. Long-term and short-term surgical outcomes of laparoscopic versus open liver resection for hepatocellular carcinoma: might laparoscopic approach be better in early HCC? Surg Endosc. 2019;33(4):1131-1139. doi:10.1007/ s00464-018-6372-0

2. Petersen PL, Stjernholm P, Kristiansen VB, et al. The beneficial effect of transversus abdominis plane block after laparoscopic cholecystectomy in day-case surgery: a randomized clinical trial. Anesth Analg. 2012;115(3):527-533. doi:10.1213/ANE.0b013e318261f16e

3. Mitra S, Khandelwal P, Roberts K, Kumar S, Vadivelu N. Pain relief in laparoscopic cholecystectomy - a review of the current options. Pain Pract. 2012;12(6):485-496. doi:10.1111/j.1533-2500.2011.00513.x

4. Tan M, Law LS, Gan TJ. Optimizing pain management to facilitate enhanced recovery after surgery pathways. Can J Anaesth. 2015;62 (2):203-218. doi:10.1007/s12630-014-0275-x

5. Abrahams MS, Horn JL, Noles LM, Aziz MF. Evidence-based medicine: ultrasound guidance for truncal blocks. Reg Anesth Pain Med. 2010;35(2 Suppl):S36-S42. doi:10.1097/AAP.0b013e3181d32841

6. El-Dawlatly AA, Turkistani A, Kettner SC, et al. Ultrasound-guided transversus abdominis plane block: description of a new technique and comparison with conventional systemic analgesia during laparoscopic cholecystectomy. Br J Anaesth. 2009;102(6):763-767. doi:10.1093/ bja/aep067

7. Borglum J, Jensen K, Christensen AF, et al. Distribution patterns, dermatomal anesthesia, and ropivacaine serum concentrations after bilateral dual transversus abdominis plane block. Reg Anesth Pain Med. 2012;37(3):294-301. doi:10.1097/AAP.0b013e31824c20a9

8. Peng K, Ji FH, Liu HY, Wu SR. Ultrasound-guided transversus abdominis plane block for analgesia in laparoscopic cholecystectomy: a systematic review and meta-analysis. Med Princ Pract. 2016;25 (3):237-246. doi:10.1159/000444688
9. Bashandy GM, Elkholy AH. Reducing postoperative opioid consumption by adding an ultrasound-guided rectus sheath block to multimodal analgesia for abdominal cancer surgery with midline incision. Anesth Pain Med. 2014;4(3):e18263. doi:10.5812/ aapm. 18263

10. Champaneria R, Shah L, Geoghegan J, Gupta JK, Daniels JP. Analgesic effectiveness of transversus abdominis plane blocks after hysterectomy: a meta-analysis. Eur J Obstet Gynecol Reprod Biol. 2013;166(1):1-9. doi:10.1016/j.ejogrb.2012.09.012

11. Gao T, Zhang JJ, Xi FC, et al. Evaluation of transversus abdominis plane (TAP) block in hernia surgery: a meta-analysis. Clin J Pain. 2017;33(4):369-375. doi:10.1097/AJP.0000000000000412

12. Iwata M, Kuzumoto N, Kmoto K, et al. [Effects of RSB and TAPB on postoperative pain in laparoscopic cholecystectomy]. Masui. 2017;66(2):127-130.

13. Kang SB, Park JW, Jeong SY, et al. Open versus laparoscopic surgery for mid or low rectal cancer after neoadjuvant chemoradiotherapy (COREAN trial): short-term outcomes of an open-label randomised controlled trial. Lancet Oncol. 2010;11(7):637-645. doi:10.1016/ S1470-2045(10)70131-5

14. Li JF, Bai DS, Jiang GQ, Chen P, Jin SJ, Zhu ZX. Laparoscopic and open splenectomy and hepatectomy. JSLS. 2017;21(1). doi:10.4293/ JSLS.2016.000104

15. Alexander JI. Pain after laparoscopy. $B r \quad J$ Anaesth. 1997;79 (3):369-378. doi:10.1093/bja/79.3.369

16. Latimer RG, Dickman M, Day WC, Gunn ML, Schmidt CD. Ventilatory patterns and pulmonary complications after upper abdominal surgery determined by preoperative and postoperative computerized spirometry and blood gas analysis. Am J Surg. 1971;122 (5):622-632. doi:10.1016/0002-9610(71)90290-X

17. Bisgaard T, Klarskov B, Rosenberg J, Kehlet H. Characteristics and prediction of early pain after laparoscopic cholecystectomy. Pain. 2001;90(3):261-269. doi:10.1016/S0304-3959(00)00406-1

18. Abdelsalam K, Mohamdin OW. Ultrasound-guided rectus sheath and transversus abdominis plane blocks for perioperative analgesia in upper abdominal surgery: a randomized controlled study. Saudi J Anaesth. 2016;10(1):25-28. doi:10.4103/1658-354X.169470
Therapeutics and Clinical Risk Management

\section{Publish your work in this journal}

Therapeutics and Clinical Risk Management is an international, peerreviewed journal of clinical therapeutics and risk management, focusing on concise rapid reporting of clinical studies in all therapeutic areas, outcomes, safety, and programs for the effective, safe, and sustained use of medicines. This journal is indexed on PubMed Central, CAS,
EMBase, Scopus and the Elsevier Bibliographic databases. The manuscript management system is completely online and includes a very quick and fair peer-review system, which is all easy to use. Visit http://www.dovepress.com/testimonials.php to read real quotes from published authors 